\title{
Conformity of pre-design studies on Lakhta- Center influence on the Saint Petersburg historical panorama and scenery spots
}

\author{
Oleg Fedorov ${ }^{1, *}$ and Yury Lobanov ${ }^{1}$ \\ ${ }^{1}$ Saint Petersburg State University of Architecture and Civil Engineering, 190005, St. Petersburg, \\ Russia
}

\begin{abstract}
The present study is aimed to identify influence of LakhtaCenter visibility by means of photofixation results' analysis and their comparison with the results of the landscape and visual analysis performed by the Saint Petersburg Regional Committee of the International Council on Monuments and Sights (ICOMOS), report on research of Lakhta-Center high-rise dominant visibility influence on Saint Petersburg protected panoramas (2012), and assessment analysis of requested deviations' influence on formation of compositional and environmental characteristics of the urban environment based on a 3D reference model of the Saint Petersburg territory (2011). The study is supported by actual photos of cityscapes, thus, allowing assessing the situation reasonably and rationally. The performed work resulted in graphic materials, including photos and maps with reviews and classification of Lakhta-Center visibility upon perception of the main city panoramas from the tourist route combining the most popular sights of the city.
\end{abstract}

\section{Introduction}

Epigraph: "Petersburg was forming as a city of horizontals. The flat lowland surface ... dictated ... the flat development of the city, sometimes emphasized by high-rise compositions. ... Not competing with traditional city dominants because of their remoteness from historical buildings, the high-rise composition on the coast of the Gulf of Finland will become an organizing element and a point of attraction for business and new development projects in a developing area of the city" [1].

The construction of Lakhta-Center takes place in the Primorsky district of Saint Petersburg, $9 \mathrm{~km}$ from the historical center. The Russian State Hydrometeorological University carried out a special assessment of the climatic characteristics in the Primorsky district, which concluded that, due to the cloudy weather prevailing in Saint Petersburg (237-256 days a year), the visibility of the upper part of a high-rise building will mostly be difficult (constant visibility will be available only for the lower part of the building (lower $100-200 \mathrm{~m})$.

\footnotetext{
* Corresponding author: oleg proart@,mail.ru
} 
At the moment, a complete objective description of the influence of the constructed Lakhta-Center complex on the historical panorama of Saint Petersburg and the historical suburbs is not found in open sources. Accordingly, in connection with the recent achievement of the high-altitude dominant of the complex of its upper mark and the presence of several completed pre-project studies, it becomes necessary to create a reliable fixation and description of the real situation, as well as verification of pre-project studies.

The importance of preserving the identity of the environment of historical cities in general, and the UNESCO-protected historical center of Saint Petersburg in particular, was also one of the main prerequisites for conducting the corresponding study.

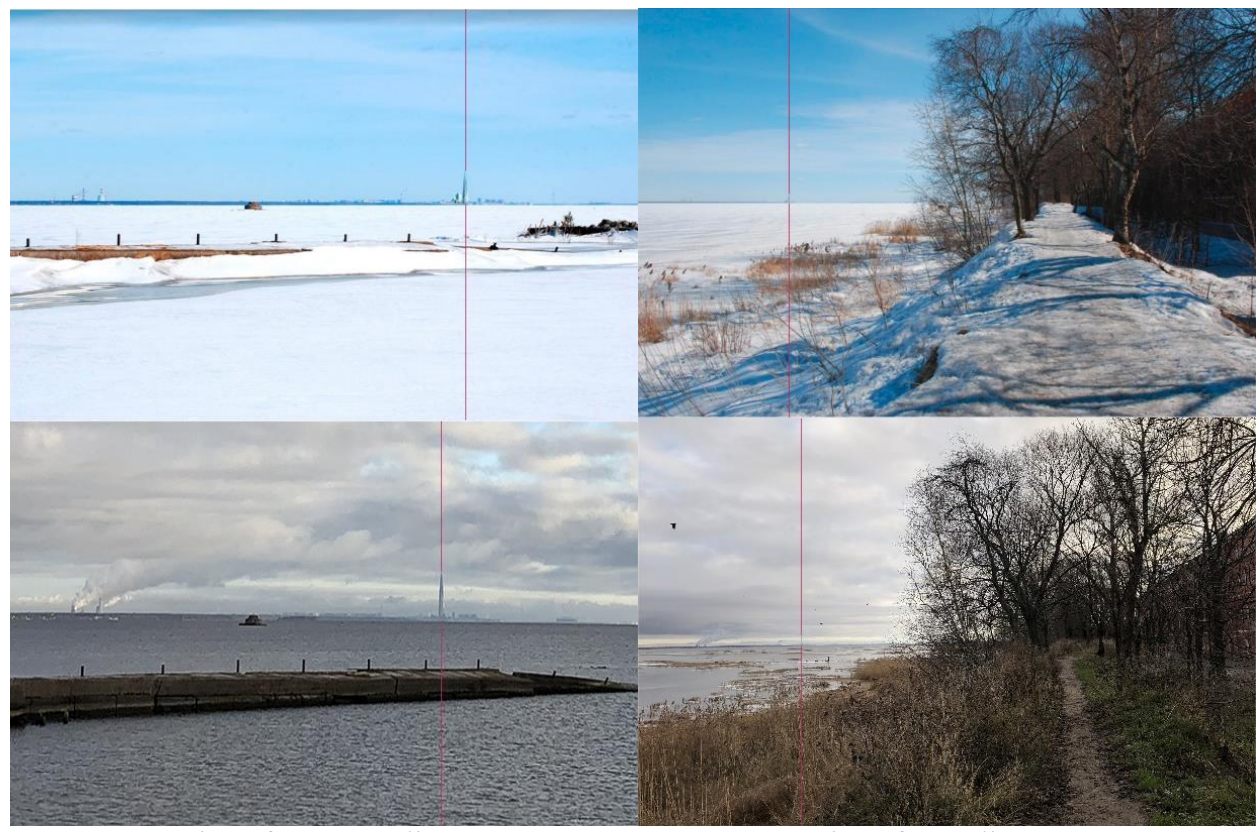

Option of non-compliance

Option of compliance

Fig. 1. Comparison of pre-project photofixation with the existing situation.

\section{Materials and Methods}

The initial stage of verification was the study of pre-project studies of the influence of Lakhta-Center on the historical panorama of Saint Petersburg and the historical suburbs and methods for their implementation [2-5].

Based on this analysis, photographic fixation points were determined, a route and a plan of field work were formed. For photographic fixation, we used the cameras of mobile phones with a focal length of $28 \mathrm{~mm}$, which brings the result closer to the real perception of the environment by the human eye (focal length of $20 \mathrm{~mm}$ ). However, an analysis of the work revealed an ambiguous approach to making photographic fixations in the Report of the International Council on Monuments and Sights and the Saint Petersburg Regional Committee (ICOMOS St. Petersburg) "Assessing the potential impact of Lakhta-Center on the outstanding universal value of the World Heritage Site "Historical Center of Saint Petersburg and related complexes of monuments" [2]. Some pictures were taken using a telephoto lens with a focal length of approximately $200 \mathrm{~mm}$.

The obtained data from field work (photofixation) were processed for maximum compliance with pre-project studies and arranged in a sheet format (see Fig. 1). The pink vertical line indicates the axis of the vertical dominant of the Lakhta-Center complex. 


\section{Results and Discussion}

\subsection{Theoretical background of studies of the skyline of Saint Petersburg, the influence of new dominants on it}

Given the theory and practice in urban planning [6-15], it can be assumed that the development of the compositional and spatial organization of dominants should be based on several interrelated principles. The main task is to create a meaningful and cohesive silhouette with vertical accents, as well as to support their location with the compositional basis of the settlement, where the main verticals will be of particular importance and give the city a distinctive look that will designate not only the central parts, but also the outskirts that are subordinate to central dominants.

In the collection "Reconstruction of the historical zones of cities", Yu. N. Kishik wrote that social processes and connections become more active in the urban environment if the environment is saturated with objects of social significance associated with everyday life, work, leisure, and public spaces [6]. The unification of the city's panorama is achieved both by the connecting elements of the construction, and by dissecting ones located in various functional and spatial zones. Spatial relationships solve the planning structure of the city, the organization of the urban environment as a deeply spatial composition. Ensuring such integration and correctly located dominants are important for aesthetic expressiveness and perception of three-dimensional composition. The connecting factor for this approach will be not only panoramic view perspectives, called "golden points" or "postcard views", but also the human perception of architectural verticals.

Yu.N. Kishik identified three categories of verticals that are used for large (largest) and medium-sized cities: the first - the highest order, the second and the third. High-altitude dominants of the first order serve to separate and unite the urban environment, setting the main spatial relationships, reference points. They are placed at large intervals that correspond to the natural module. Second-order verticals serve to complement, maintain and arrange the basic spatial relationships; they are also used in the landscape to give emphasis to the composition. Third-order dominants set the rhythm for high-rise buildings and add color to the perception of urban development. The listed dominants have similarities not only in type, size, shape, composition, but also in the level of organization of the urban environment. To balance the verticals, a combination of leading spatial relationships is used. Therefore, the interconnected nodes connecting the urban pattern are usually located at the intersection of the main axes of the composition. Dominants of the second category have a freer location in places of leading spatial connections. Verticals of the third category serve for arranging accents, set the rhythm and main directions to public areas [7].

N.N. Baranov studied modern and historical high-rise, dominant objects and their influence on the silhouette of Milan, London, Paris and other European cities. In his works [8], he shared the opinion that in urban planning, a set of high-rise dominants should create a composition of verticals as independent objects that form the city's system. It is necessary to harmonize this set both in relation to the artificial landscape - the architectural and construction structure, and the natural landscape - the surrounding natural environment. Complex high-altitude compositions, peripheral local heights, accenting elements should be integrated with the architectural and planning appearance of the city.

Of course, the presence and distribution of high-altitude dominants, their species characteristics are an important factor in influencing the visual quality of the urban environment, stimulating or, conversely, worsening social interactions and processes in the city, and developing the economic and technological potential of the city. Therefore, it 
determines the sustainable development of the city, the promotion of the architecture of eco-sustainable construction projects [16.17].

\subsection{A brief description of the analyzed pre-design studies}

\subsubsection{Saint Petersburg Regional Committee of the International Council on Monuments and Sights (ICOMOS St. Petersburg) "Assessing the Impact on Heritage. The potential impact of Lakhta-Center on the outstanding universal value of the World Heritage Site "The Historical Center of Saint Petersburg and its associated complexes of monuments" "(2013) [2]}

The work was created for the pre-project assessment of the possible negative consequences of building a skyscraper for the World Heritage Site "The Historical Center of Saint Petersburg and its associated complexes of monuments" and their possible prevention by making adjustments to the architectural concept of the project.

The impact assessment methodology is based on the ICOMOS "Guidelines for the determination of influence on heritage for World Heritage Sites". Three historical landscape complexes (HLC), which are the most exposed to influence, were allocated from the composition of the World Heritage Site. Subsequently, after conducting field studies, photographic fixation and modeling, for each HLC, the scale of the influence effects (unchanged / minor / small / moderate / significant) and the resource value class (very high / high / medium / low / minor / with unknown potential) were analyzed. These are two parameters by which the classification table was compiled.

The study provides a detailed description of each investigated fragment of the city and region, with the application of parts to be preserved and photographic fixation with a schematic image of Lakhta-Center. Number of points considered: 18.

\subsubsection{Saint-Petersburg State Polytechnic University "Study of the impact of the visibility of the high-altitude dominant of Lakhta-Center on protected panoramas of Saint Petersburg" (2012) [3]}

In this study, the authors carried out work to create a realistic image of a skyscraper with materials used in the construction of Lakhta- Center - their illumination, refractions and reflections of light, as well as caustic lighting effects. The influence of weather conditions on the perception of visibility is emphasized, based on air transparency coefficients; as a result, two versions of photographs with the Lakhta-Center model in cloudy and sunny weather, built-in by the method of numerical simulation, are provided.

Number of points considered: 9 .

3.2.3 State Research and Design Center of St. Petersburg Master Plan, commissioned by the "Public and business center "Okhta"' CJSC "Analysis of the assessment of the impact of the requested deviations on the formation of the compositional and environmental characteristics of the urban environment based on the three-dimensional basic model of the locality of Saint Petersburg" (2011) [4]

The basis of the analysis is the Methodology for checking the height of the objects proposed for construction in terms of the possible impact on the silhouette organization of the territory of Saint Petersburg, created by the State Institution "State Research and Design Center of St. Petersburg Master Plan" in accordance with the Thematic Plan of the Committee for City Planning and Architecture for 2009. 
The initial data for the work was the Lakhta-Center design model located in the basic three-dimensional model of the terrain of Saint Petersburg. By using computer programs, the created map of visibility zones was combined with a map of points falling into protected historical views (both falling and not falling within the scope of the law No. 820-7).

It is noteworthy that as a result, the authors presented 2 types of visualizations - with and without green spaces, given the difference in views by season, which improves the quality of the study. Number of points considered: 14 .

3.2.4 Institute of Geographic Information Technologies LLC, commissioned by the "Public and business center "Okhta"" CJSC "Analysis of the assessment of the impact of requested deviations on the formation of the compositional and environmental characteristics of the urban environment based on a threedimensional basic model of the locality of Saint Petersburg" (2011) [5]

The initial data for the work was the Lakhta-Center model placed in the basic threedimensional model of the terrain of Saint Petersburg. The authors of the study, based on law No. 820-7, take into account the remoteness of protected objects at a distance of more than $6 \mathrm{~km}$, which corresponds to the distance at which the clarity of the silhouette and the effect on the visual perception of the panorama are lost. Considering this position, sights that are affected are divided into groups according to a combination of remoteness (within/outside $6 \mathrm{~km}$ ) and the presence of protected elements.

Number of points considered: 21 .

In the considered pre-design studies, various techniques were used, which are based mainly on three-dimensional modeling of the Lakhta-Center building and placing it in an existing city model (or a schematic image without reliance on the model). Proceeding from this, it is obvious that verification of the obtained data is necessary in order to verify their authenticity and their compliance with the real situation.

\section{Conclusions}

To verify the correctness of the methodology of pre-project study (computer visualization), photographs were taken at all available points for comparison with visualizations of studies of the influence of dominant visibility on the urban environment of Saint Petersburg [18].

\subsection{Conclusions on the Report of the International Council on Monuments and Sights and the Saint Petersburg Regional Committee (ICOMOS St. Petersburg) "Assessment of the potential impact of Lakhta-Center on the outstanding universal value of the World Heritage Site "The Historic Center of Saint Petersburg and its associated complexes of monuments"}

During the verification of the pre-project study, 18 points out of 20 were examined (the incomplete number of points considered was due to the inaccessibility of the two locations currently analyzed in the study). On 15 of them, photos correspond to the expected results: the Lakhta-Center building is in the same place and has the dimensions corresponding to the intended ones.

Thus, the Report of the International Council on Monuments and Sights and the Saint Petersburg Regional Committee (ICOMOS St. Petersburg) "Assessment of the potential impact of Lakhta-Center on the outstanding universal value of the World Heritage Site "The Historical Center of Saint Petersburg and its associated complexes of monuments" " is $75 \%$ correct. 


\subsection{Conclusions on the Report on the research work "Study of the impact of visibility of the high-altitude dominant of Lakhta-Center on the protected panoramas of Saint Petersburg"}

During the verification of the pre-design study, 9 points were examined, on 8 of which the photos correspond to the expected results (the weather factor is taken into account: 1 photo was taken in cloudy weather, the Lakhta-Center building is not visible in this photo).

Thus, the report on the research work "Research on the impact of visibility of the highaltitude dominant of Lakhta-Center on the protected panoramas of Saint Petersburg" is $89 \%$ correct.

4.3 Conclusions on the "Analysis of the assessment of the impact of the requested deviations on the formation of the compositional and environmental characteristics of the urban environment based on the threedimensional basic model of the locality of Saint Petersburg" (performed by the State Institution "State Research and Design Center of St. Petersburg Master Plan")

During the verification of the pre-project study, all 14 points were examined, on 12 of which the photos correspond to the expected results.

Thus, the analysis of the assessment of the influence of the requested deviations on the formation of the compositional and environmental characteristics of the urban environment based on the three-dimensional basic model of the locality of Saint Petersburg (performed by the State Institution "State Research and Design Center of St. Petersburg Master Plan") is $86 \%$ correct.

\subsection{Conclusions on the "Analysis of the assessment of the impact of the requested deviations on the formation of the compositional and environmental characteristics of the urban environment based on the three- dimensional basic model of the locality of Saint Petersburg" (performed by the Institute of Geographic Information Technologies LLC)}

During the verification of the pre-design study, 23 points were considered. At all the considered points, the photos correspond to the expected results (the weather factor is taken into account: 4 photos were taken in cloudy weather, the Lakhta-Center building is not visible in these photos).

Thus, the analysis of the assessment of the impact of the requested deviations on the formation of the compositional and environmental characteristics of the urban environment based on the three-dimensional basic model of the locality of Saint Petersburg (performed by the Institute of Geographic Information Technologies LLC) is 100\% correct.

Summarizing the above results of the analysis of pre-design studies, it can be concluded that the authors performed a high quality studies - the correspondence to the real situation is observed in more than $80 \%$ of images. During the photofixation, important factors were found that affect the visibility of Lakhta-Center, such as: weather conditions (taken into account in a study performed by the St. Petersburg Polytechnic University), difference in perception at different times of the year (taken into account in a study performed by the State Research and Design Center of St. Petersburg Master Plan), differences in the features of the visual perception of the human eye and cameras with different characteristics of the focal length. It is worth noting that when the visual characteristics of Lakhta-Center at some points of photographic fixation did not match some points from pre-project studies, as a rule, an exaggeration of the height in the visualizations of the expected result was observed 
compared to the real situation. In general, the methods applied by companies in conducting pre-project studies on the impact of the Lakhta-Center complex on panoramas and views of Saint Petersburg can be considered successful and provide the correct result.

The authors are grateful to St. Petersburg State University of Architecture and Civil Engineering represented by Rector Evgeny Ivanovich Rybnov, Head of the Department of Scientific Work Natalya Borisovna Lukmanova and Dean of the Faculty of Architecture Fedor Viktorovich Perov for their support in conducting research and providing an intra-university grant for the development of this topic. The authors are grateful to our students - Anastasia Metlitskaya, Julia Beloslyudtseva and Dinara Fazlieva, who actively participated in this work and made a significant contribution to its preparation and completion.

\section{References}

1. Lakhta Center. http://lakhta.center/en/

2. Report. Heritage Impact Assessment. http://www.dmitrieva.org/files/Jahta_text_raboty.pdf

3. E. Voskresenskaya , V. Snetkov, A. Tebryaev, E3S Web of Conferences 33, 03051 (2018)

4. M. Granstrem, M. Zolotareva, T. Slavina, E3S Web of Conferences 33, 01028 (2018).

5. L.P. Lavrov, F.V. Perov, J Bull.Civ.Eng. 5, 58, 16-27 (2016)

6. D. S. Likhachev J.O.Her. 1, 8-13(1989)

7. O.P. Fedorov, J Bull.Civ.Eng., 6, 59 (2016)

8. O.P. Fedorov, J Electr.sc. 11,1 (2016)

9. http://fundamental-research.ru/

10. Milja Penić, Golovina Svetlana, Procedia Engineering, 117, (2015), 883-890, https://doi.org/10.1016/j.proeng.2015.08.165

11. Cemil Akcay, Baris Sayin, Baris Yildizlar, Construction and Building Materials, 132, 1 383-394 (2017) https://doi.org/10.1016/j.conbuildmat.2016.12.002

12. Hülya Yüceer, Journal of Cultural Heritage, 13, 4,419-425 (2012) https://doi.org/10.1016/j.culher.2011.12.002 